\title{
SHORTER NOTES
}

The purpose of this department is to publish very short papers of an unusually elegant and polished character, for which there is no other outlet.

\section{A PROOF OF THE PRINCIPLE OF LOCAL REFLEXIVITY}

\section{CHARLES STEGALL}

Abstract. A quite elementary proof of the principle of local reflexivity is given.

Our purpose here is to give a proof of the "principle of local reflexivity" (using only the various forms of the Hahn-Banach theorem) as given in [1] and in an improved version in [2]. Our notation is standard. By $X, Y$ and $Z$ we shall denote Banach spaces and $J_{X}$ will denote the canonical embedding of $X$ into its second dual $X^{\prime \prime}$. An operator is a continuous linear function.

We shall require only the three following lemmas.

LEMMA 1. Let $T: X \rightarrow Y$ be a closed operator. If $x^{\prime \prime}$ is in $X^{\prime \prime}$ and $y$ is in $Y$ such that $T^{\prime \prime} x^{\prime \prime}=J_{Y} y$ then, for any $\partial>0$ there exists an $x$ in $X$ such that

$$
\|x\|<(1+\partial)\left\|x^{\prime \prime}\right\|
$$

and $T x=y$.

LEMMA 2. Let $T: X \rightarrow Y$ and $S: X \rightarrow Z$ be operators such that $T$ is closed and $S$ has finite rank. Then $U: X \rightarrow Y \times Z$ defined by $U x=(T x, S x)$ is a closed operator.

Lemma 3. Let $0<\partial<\frac{1}{4}$ and $T: X \rightarrow Y$ be an operator such that $X$ is finite dimensional and

$$
(1+\partial)^{-1} \leqslant\left\|T x_{i}\right\|<(1+\partial)
$$

where $\left\{x_{i}\right\}$ is any $\partial-$ net for the unit sphere of $X$. Then $T$ is invertible and

$$
\|T\|\left\|T^{-1}\right\| \leqslant\left(\frac{1+\partial}{1-\partial}\right)\left(\frac{1}{1+\partial}-\frac{\partial(1+\partial)}{1-\partial}\right)^{-1}=\vartheta(\partial) .
$$

Received by the editors July 21, 1978.

AMS (MOS) subject classifications (1970). Primary 46B99.

Key words and phrases. Banach spaces. 
Lemma 1 follows immediately from the separation theorem. Lemma 2 is easily proved by observing that $U^{\prime}$ is closed and Lemma 3 is a routine computation using the triangle inequality.

THEOREM [1], [2]. Let $E$ and $F$ be finite dimensional subspaces of $X^{\prime \prime}$ and $X^{\prime}$, respectively, and let $\varepsilon>0$. Then there exist an operator $T: E \rightarrow X$ such that $\|T\|\left\|T^{-1}\right\|<1+\varepsilon, x^{\prime}\left(T x^{\prime \prime}\right)=x^{\prime \prime}\left(x^{\prime}\right)$ for all $x^{\prime \prime}$ in $E$ and all $x^{\prime}$ in $F$, and $T x^{\prime \prime}=x$ if $J_{X} x=x^{\prime \prime}$ is in $E$.

Proof. Choose $\partial>0$ so that $\vartheta(\partial)<1+\varepsilon$ where $\vartheta$ is as in Lemma 3. Choose norm one elements $a_{1}^{\prime}, a_{2}^{\prime}, \ldots, a_{m}^{\prime}$ in $X^{\prime}$ containing a basis of $F$ and such that

$$
\left\|x^{\prime \prime}\right\|<(1+\partial) \sup _{j}\left|x^{\prime \prime}\left(a_{j}^{\prime}\right)\right|
$$

for all $x^{\prime \prime}$ in $E$. Choose $b_{1}^{\prime \prime}, b_{2}^{\prime \prime}, \ldots, b_{n}^{\prime \prime}$ a $\partial$-net for the unit sphere of $E$ such that $b_{1}^{\prime \prime}, \ldots, b_{k}^{\prime \prime}$ is a basis for $J_{X} X \cap E$ and $b_{1}^{\prime \prime}, \ldots, b_{r}^{\prime \prime}, r>k$, is a basis for $E$. Then, for $1 \leqslant p \leqslant q=n-r$, we have the unique scalars $\left\{t_{p, i}\right\}, 1<i<r$, such that

$$
b_{r+p}^{\prime \prime}=\sum_{1<i<r} t_{p, i} b_{i}^{\prime \prime}
$$

Define for $1 \leqslant p \leqslant q$

$$
s_{p, i}= \begin{cases}t_{p, i}, & i \leqslant r \\ -1, & i=r+p, \\ 0, & r<i \leqslant n \text { and } i \neq r+p .\end{cases}
$$

Define $A_{0}: X^{n} \rightarrow X^{k+q}$ by

$$
A_{0}\left(x_{1}, \ldots, x_{n}\right)=\left(x_{1}, \ldots, x_{k} ;\left(\sum_{1<i<n} s_{p, i} x_{i}\right)\right)
$$

for $1<p<q$ where $X^{n}$ and $X^{k+q}$ are the usual product spaces with the sup norm. The operator $A_{0}$ is onto since the matrix $\left(s_{p, i}\right)$ has rank $q$. Define $A$ : $X^{n} \rightarrow Z=X^{k+q} \times \mathbf{C}^{n m}$ by

$$
A\left(x_{1}, \ldots, x_{n}\right)=\left(A_{0}\left(x_{1}, \ldots, x_{n}\right) ;\left(a_{j}^{\prime}\left(x_{i}\right)\right)\right)
$$

for $1<j<m$ and $1 \leqslant i \leqslant n$. By Lemma $2, A$ is a closed operator. Observe that $A^{\prime \prime}\left(b_{1}^{\prime \prime}, \ldots, b_{n}^{\prime \prime}\right)$ is in $J_{Z} Z$. Therefore, by Lemma 1 , there exists $\left(b_{1}, \ldots, b_{n}\right)$ in $X^{n}$,

$$
\sup _{i}\left\|b_{i}\right\|<(1+\partial) \sup _{i}\left\|b_{i}^{\prime \prime}\right\|=1+\partial
$$

such that $J_{Z} A\left(b_{1}, \ldots, b_{n}\right)=A^{\prime \prime}\left(b_{1}^{\prime \prime}, \ldots, b_{n}^{\prime \prime}\right)$. Define the operator $T: E \rightarrow X$ such that $T b_{i}^{\prime \prime}=b_{i}$ for $1 \leqslant i \leqslant r$. For $1 \leqslant p \leqslant q$, we have that $\sum_{1<i<n} s_{p, i} b_{i}^{\prime \prime}$ $=0$ and $\Sigma_{1<i<n} s_{p, i} b_{i}=0$ which gives that $T b_{i}^{\prime \prime}=b_{i}$ also for $r<i<n$. To apply Lemma 3 and complete the proof we need only observe that for each $i$,

$$
\left\|T b_{i}^{\prime \prime}\right\| \geqslant \sup _{j}\left|a_{j}^{\prime}\left(T b_{i}^{\prime \prime}\right)\right|=\sup _{j}\left|b_{i}^{\prime \prime}\left(a_{j}^{\prime}\right)\right|>(1+\partial)^{-1} \text {. }
$$


This proof was presented at the Functional Analysis Conference at Oberwolfach in October, 1974.

\section{REFERENCES}

1. J. Lindenstrauss and H. Rosenthal, The $\mathfrak{L}_{p}$ spaces, Israel J. Math. 7 (1969), 325-349.

2. W. B. Johnson, H. Rosenthal and M. Zippin, On bases, finite dimensional decompositions and weaker structures in Banach spaces, Israel J. Math. 9 (1971), 488-506.

Mathematisches InstTtut, Universität ErLANGen-NÜrnberg, 8520 ERLANGen, Germany

Current address: Institut für Mathematik, Johannes Kepler Universität, A-4045 Linz, Austria 